\title{
Uso continuado de ferramenta computacional baseada em questões do ENADE para a avaliação diagnóstica de alunos de Sistemas de Informação: um estudo de caso
}

\author{
Pedro L. S. Barbosa ${ }^{1}$, Windson V. de Carvalho ${ }^{1}$ \\ ${ }^{1}$ Universidade Federal do Ceará (UFC) - Fortaleza, CE - Brazil \\ pedro.barbosaeifce.edu.br, windsonevirtual.ufc.br
}

\begin{abstract}
This paper reports the diagnostic evaluation of students in an Information Systems (IS) course supported by a Web system, called Questione. This system stores and indexes questions with structures similar to the items applied in Enade. We report the evolution of the students' competencies and how the Questione's data served for decision making. For that, we collected the feedback of the professors involved in this IS course. When analyzing all the elements of this research, we can conclude that the Questione system was fundamental to systematize the diagnostic evaluation, allowing the cataloguing of the questions and the application of the simulations to become a routine and straightforward task within the course.
\end{abstract}

Resumo. Este trabalho relata a avaliação diagnóstica de estudantes de um curso de Sistemas de Informação (SI) apoiada por um sistema Web, chamado Questione, que armazena e indexa questões com estruturas semelhantes às questões aplicadas no Enade. $O$ artigo relata a evolução dos estudantes com relação às competências mensuradas e como esses dados serviram para a tomada de decisão de um curso de SI, por meio do feedback coletado com os professores que participaram do processo. Ao analisar todos os elementos desta pesquisa, pode-se concluir que o sistema Questione foi fundamental para sistematizar a avaliação diagnóstica, permitindo que a catalogação das questões e a aplicação dos simulados se tornasse uma tarefa simples e rotineira dentro do curso.

\section{Introdução}

Em um contexto onde se espera garantir a qualidade da educação, obter indicadores acerca das competências dos estudantes durante toda a sua vida acadêmica em um determinado curso é de extrema importância. Realizar avaliações diagnósticas com os alunos é fundamental para se ter uma ação estratégica no âmbito de um curso ou de uma instituição. Proporciona um ganho tanto na formação profissional dos estudantes como no aspecto de formar um profissional com mais qualidade no mercado de trabalho. Além disso, pode indiretamente ou diretamente aumentar os indicadores das avaliações externas de um curso de graduação. O Exame Nacional do Desempenho dos Estudantes (Enade) que é regulamentado pelo Sistema Nacional da Avaliação da Educação Superior 
(Sinaes) e foi criado pela Lei $\mathrm{n}^{\circ} 10.861$, de 14 de abril de 2004 (BRASIL, 2004), é exemplo de uma avaliação externa.

Montar e aplicar avaliações simples muitas vezes não impõe a necessidade de uma informatização do processo, pois, em geral, não se busca investigar competências dos estudantes e o grupo de alunos é pequeno. Mas quando se pretende buscar questões já aplicadas em avaliações externas ou criar questões novas mantendo um banco de questões próprio, a situação requer um cuidado e atenção muito maior. Essas avaliações necessitam, por exemplo, estar catalogadas por qual competência e quais objetos de conhecimento (assunto) são trabalhados. Essa dificuldade da avaliação se simplifica com a adoção de um sistema informatizado.

Nos dias atuais, as novas tecnologias oferecem uma nova estrutura que pode influenciar aspectos positivos e negativos na vida de todos os indivíduos (HINOJO-LUCENA et al., 2020). A educação é uma área que possui aspectos que constantemente estão sendo afetados pelas tecnologias, seja no ensino presencial ou ensino a distância. Ferramentas que auxiliam na aplicação e correção de questionários de avaliação, podem ser colocadas como um aspecto positivo das novas tecnologias na educação, pois automatiza processos burocráticos para o professor, como a própria correção. Nesse ponto, o tempo gasto para a correção das avaliações, nessa nova perspectiva, pode ser melhor aproveitado com o planejamento de ações para melhoria do processo de ensino aprendizagem. Como exemplo dessas ferramentas, se tem: Kahoot, Google Forms, Quizizz, Mentimeter e o próprio Questione ${ }^{1}$, que será melhor apresentado em seções posteriores.

$\mathrm{Na}$ literatura, existem trabalhos que investigam o uso dessas ferramentas dentro do processo de ensino aprendizagem. No trabalho de Lima et al. (2018), por exemplo, é apresentada uma metodologia para classificação e análise de perguntas das avaliações do Enade do curso de Bacharelado em Ciência da Computação por conteúdo, de acordo com as Diretrizes Curriculares do Curso. Por meio da classificação, Lima et. al. (2018) relatam resultados que permitem uma melhor compreensão do desempenho do aluno com base no conhecimento do domínio representado no exame, para isso foi implementado um protótipo denominado SysEnade que ajuda na classificação das questões de acordo com um dicionário de palavras definido para cada conteúdo.

Seguindo uma abordagem similar, o sistema Questione, avaliado neste trabalho, consiste em um sistema de armazenamento e indexação de questões com estruturas semelhantes às questões aplicadas no Enade. Por meio do sistema Questione, é possível também montar, aplicar e analisar avaliações. Após as aplicações, o sistema Questione permite ao elaborador da avaliação uma análise por competência e objetos de conhecimento. Neste artigo, em particular, o objetivo é relatar o processo utilizado pelo colegiado do curso de Bacharelado em Sistemas de Informação (BSI) do Instituto Federal de Educação, Ciência e Tecnologia do Ceará - campus Cedro (IFCE) para diagnosticar os estudantes dos últimos quatro períodos com o auxílio do sistema Questione. Os resultados aqui apresentados podem servir para que profissionais da educação das Instituições do Ensino Superior (IES) possam replicar o procedimento

\footnotetext{
${ }^{1}$ https://questione.ifce.edu.br
} 
aqui utilizado com a finalidade de entender melhor os seus estudantes em relação às competências esperadas pelo perfil do egresso.

Nas seções subsequentes, apresenta-se a metodologia do trabalho (Seção 2). A apresentação do sistema Questione é feita na Seção 3. Já o resultado das avaliações dos estudantes de um estudo de caso e dados relacionados às competências que serviram para a tomada de decisão são relatados na Seção 4. Na Seção 5, é apresentado o feedback coletado com os professores que participaram do processo e, por fim, na Seção 6, são descritas as considerações finais do trabalho.

\section{Metodologia}

Este trabalho é inspirado em diagnosticar os estudantes dos quatro últimos períodos de um curso superior de BSI em relação a suas dificuldades associadas às competências que são trabalhadas no projeto pedagógico do curso. Com esse objetivo, no ano de 2018, iniciou-se o desenvolvimento de uma ferramenta que auxiliasse na catalogação de questões por competência e objeto de conhecimento. A ferramenta, que será melhor apresentada na próxima seção, foi desenvolvida por um aluno bolsista do Programa Institucional de Bolsas de Iniciação em Desenvolvimento Tecnológico e Inovação (PIBITI) e finalizada em julho de 2019.

A Figura 1 apresenta a linha do tempo que demonstra o passo a passo deste estudo. Para o desenvolvimento da primeira versão da ferramenta, foi necessário entender o formato das questões aplicadas no Exame Nacional de Desempenho dos Estudantes (Enade). Nesta etapa, foi estudada toda a legislação atual sobre o exame e as duas provas aplicadas para estudantes do curso de Sistemas de Informação (Enade 2014 e Enade 2017). Levou-se em consideração apenas as provas de 2014 e 2017 pelo fato de serem específicas para o curso de Sistemas de Informação.

Após o desenvolvimento e implantação da primeira versão do sistema, foi aplicado o primeiro simulado com os estudantes do curso de BSI do IFCE no semestre 2019.2. Para aplicação do primeiro simulado foram utilizadas as questões das provas de 2014 e 2017 do Enade. Essas questões foram cadastradas e catalogadas pelos professores do colegiado do curso. O processo de catalogação consiste em informar qual competência e qual objeto de conhecimento dispostos na portaria do Enade (e alinhadas às Diretrizes Curriculares Nacionais do curso) são contemplados na questão. O primeiro simulado foi aplicado com nove turmas, existindo turmas do primeiro ao oitavo semestre, sendo duas turmas do quarto semestre. O estudo de caso desta pesquisa, iniciou-se com esta etapa e estará restrito às últimas quatro turmas do curso.

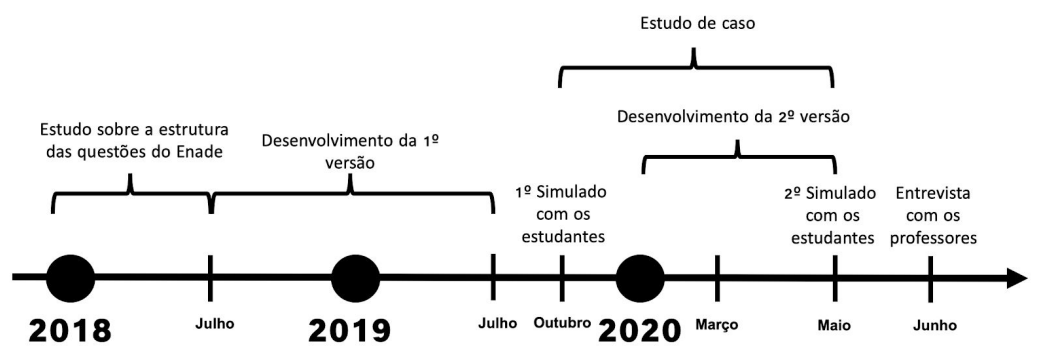

Figura 1. Timeline da pesquisa 
A aplicação do primeiro simulado mostrou a necessidade do desenvolvimento de uma segunda versão do sistema. Essa nova versão do sistema melhorou diversas funcionalidades, como a própria interface gráfica, o processo de cadastro e validação das questões, e um ambiente para que os estudantes pudessem ter um feedback de suas avaliações. Na primeira versão, os estudantes apenas respondiam a avaliação e não possuíam acesso aos resultados.

Posteriormente, foi realizado um segundo simulado. Para esta aplicação foram utilizadas questões das provas do Enade de 2014 e 2017 que não foram aplicadas no primeiro simulado e questões produzidas pelos próprios professores do colegiado do curso, os quais foram capacitados para a construção de questões no padrão exigido.

O segundo simulado foi aplicado apenas com os estudantes dos últimos períodos, que são alunos do semestre 2020.1 do sexto período (dezessete alunos), sétimo período (nove alunos), oitavo período (sete alunos) e uma turma com pendência na disciplina de Trabalho de Conclusão de Curso (nove alunos). Os alunos correspondem aos mesmos que fizeram o primeiro simulado nas turmas do semestre de 2019.2, na época sendo: quinto período (dezessete alunos), sexto período (nove alunos), sétimo período (sete alunos) e oitavo período (nove alunos). Neste artigo, esses grupos são chamados de Turma 01, Turma 02, Turma 03 e Turma 04 respectivamente. $\mathrm{O}$ motivo para a aplicação ter acontecido apenas nessas turmas se deve ao fato de que esses alunos são os mais propensos a representar o curso de BSI no Enade do ano de 2020.

Por fim, na última etapa, que ocorreu durante o mês de junho de 2020, foi preparado e enviado um formulário online para os professores do colegiado do curso de BSI que participaram de todo o processo. Esse formulário tem como finalidade, entender a percepção dos professores sobre o uso do sistema para o diagnóstico dos estudantes do curso.

\section{Banco de Questões}

O projeto do Banco de Questões do curso de BSI se iniciou em 2018, e teve sua primeira versão implantada em 2019. Em 2020 foi finalizada sua segunda versão, a qual foi nomeada de sistema Questione. Ele está disponível por meio do link https://questione.ifce.edu.br. De uma forma geral, o sistema Questione pode ser descrito como uma plataforma que mantém, centraliza e disponibiliza uma base de dados de questões catalogadas por competência, objetos de conhecimento e curso.

A estrutura utilizada para o cadastro das questões no sistema Questione, segue a mesma estrutura das questões disponíveis nas avaliações do Enade. No sistema, existem três atores: Administrador, Professor e Aluno. O ator Administrador é responsável por manter os cursos, suas competências e objetos de conhecimento. O administrador também é responsável por gerenciar o acesso dos usuários aos cursos. $\mathrm{O}$ ator Professor poderá manter questões. No cadastro da questão, o professor informa o texto base, enunciado, alternativas, o curso que a questão deve está associada, como também uma competência e no máximo três objetos de conhecimento. O professor pode criar avaliações e adicionar questões à avaliação. Após criar a avaliação, o professor poderá gerar uma aplicação da avaliação que possuirá um código da aplicação. A Figura 2 apresenta o relatório que o professor pode visualizar das respostas da aplicação da prova, onde é possível perceber a porcentagem de acertos de cada estudante e de cada questão, o tempo que o estudante usou para realizar a prova, qual alternativa cada 
estudante marcou para cada questão, como também dados das questões e dados sobre competências e objetos de conhecimento, disponibilizados na aba outros dados . Já o ator Aluno pode iniciar uma prova informando o código da aplicação. Após iniciar, o estudante pode responder as questões da avaliação. Após responder todas elas, o estudante finaliza a avaliação. $\mathrm{O}$ estudante pode então consultar se errou ou acertou a questão na tela de relatório, além de ver qual competência e objeto(s) de conhecimento a questão trabalha.

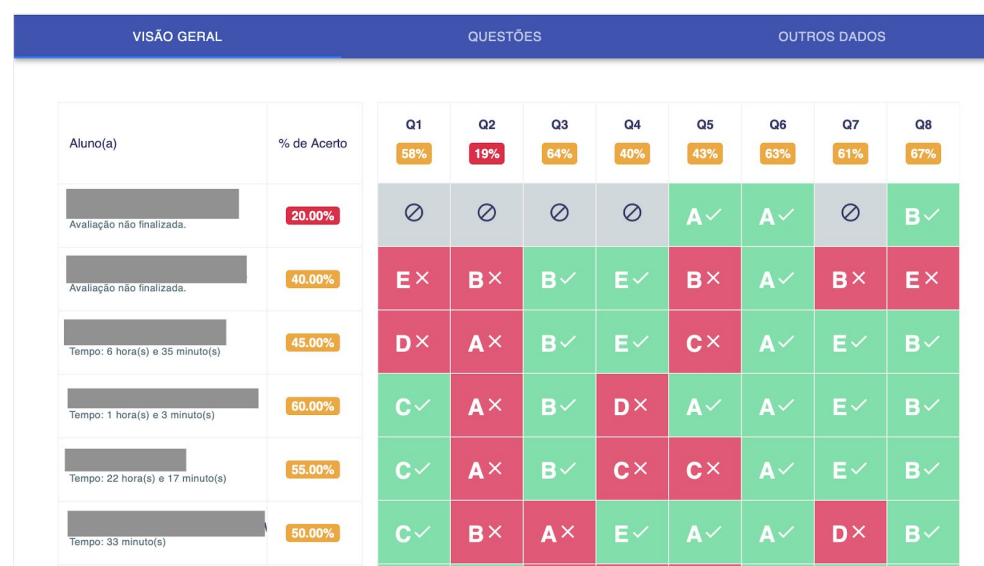

Figura 2. Relatório da avaliação (usuário professor)

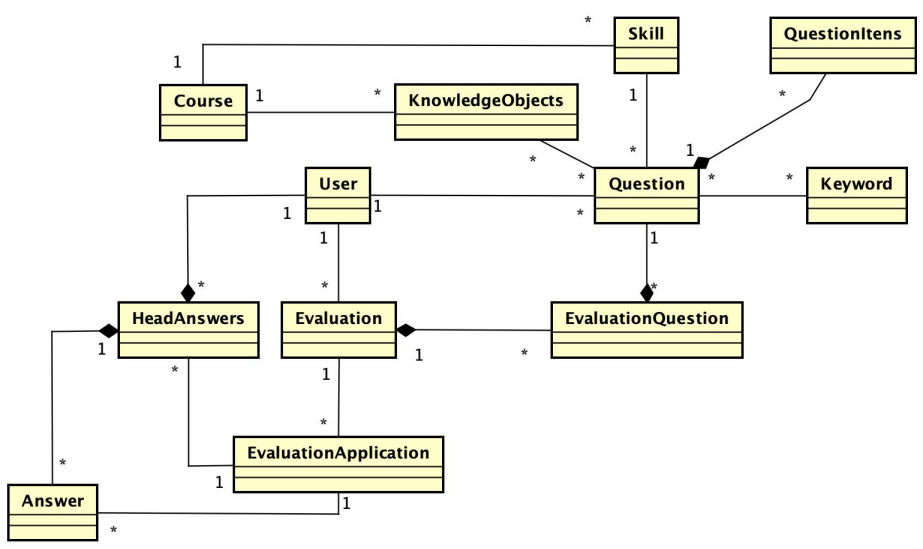

Figura 3. Modelo de Domínio - Diagrama de Classes

A Figura 3 ilustra o modelo de domínio ${ }^{2}$ do sistema como um diagrama de classes em que as operações não foram definidas. A Figura 3 mostra que um usuário (a depender do seu tipo) pode possuir um conjunto de questões que estão catalogadas por competências e objetos de conhecimentos, os quais pertencem a um curso. Um usuário do sistema também poderá criar uma ou várias avaliações e a partir dessa, gerar uma ou várias aplicações, como também, o usuário poderá responder a uma avaliação.

\section{Estudo de caso}

\footnotetext{
${ }^{2}$ Um modelo de domínio é representado por classes conceituais do mundo real em um domínio de interesse (LARMAN, 2007).
} 
O estudo de caso fruto desta pesquisa se iniciou em outubro de 2019 e finalizou em Maio de 2020. Fazem parte deste estudo quatro turmas do curso de BSI. Foram aplicados dois simulados com as quatro turmas, sendo o primeiro simulado aplicado no mês de outubro de 2019 e o segundo no mês de maio de 2020. O primeiro simulado teve onze questões para a Turma 01, Turma 02 e Turma 03. Para a Turma 04, o primeiro simulado teve dezessete questões. Todas as questões aplicadas no primeiro simulado são de origem do componente específico do Enade de 2014 e 2017 do curso de BSI. O segundo simulado teve quinze questões para todas as turmas.

Atualmente existem 82 questões cadastradas no sistema Questione que são específicas do curso de Bacharelado em Sistemas de Informação (QUESTIONE, 2020). Todos os anos o Instituto Nacional de Estudos e Pesquisas Educacionais Anísio Teixeira (INEP) libera portarias específicas de cada curso que contém os perfis, competências e objetos de conhecimento que serão cobrados na prova daquele ano. $\mathrm{O}$ curso de BSI teve sua última portaria específica em 2017, a qual possui 13 competências (BRASIL, 2017) e estão alinhadas com as Diretrizes Curriculares Nacionais para os cursos de graduação na área da Computação (BRASIl, 2016). Todas as questões cadastradas no sistema, foram catalogadas pelos professores do colegiado do curso de BSI segundo as competências e objetos de conhecimento dispostos na Portaria Inep n ${ }^{\circ} 513$ de 6 de junho de 2017 (BRASIL, 2017).

A segunda aplicação do simulado trabalhou com oito competências em todas as turmas, sendo as competências: I, IV, V, VII, IX, XI, XII, e XIII. A competência I trata de "analisar e modelar contextos sociais e organizacionais, distinguindo seus elementos constituintes e dependências entre eles", as demais competências podem ser encontradas na portaria de 2017 do curso de BSI em Brasil (2017) .

$\mathrm{Na}$ Turma 01, foram trabalhadas cinco competências na primeira aplicação, sendo as competências: IV, V, VII, XI e XII presentes nas duas aplicações. Na Turma 02, foram trabalhadas cinco competências na primeira aplicação, sendo as competências: IV, V e VII presentes nas duas aplicações. Na Turma 03, foram trabalhadas seis competências na primeira aplicação, sendo as competências: I, IV, V, VII e XII presentes nas duas aplicações. Na Turma 04, foram trabalhadas nove competências, sendo as competências IV, V, VII, IX, XI e XII presentes nas duas aplicações.

A Tabela 1 apresenta o coeficiente alfa de Cronbach para a $1^{\circ}$ e a $2^{\circ}$ aplicação dos simulados em todas as turmas. Como é perceptível, em todas as turmas houve um aumento do coeficiente, apesar da Turma 03 ter valores negativo na primeira e segunda aplicação, os quais devem ser considerados como zero, ou como escalas sem confiança (NICHOLS, 1999 apud HORA, MONTEIRO E ARICA, 2010). A Turma 02 teve o maior ganho no coeficiente da segunda aplicação em relação a primeira aplicação. $O$ aumento do valor do coeficiente na segunda aplicação representa que as respostas dos alunos na segunda aplicação foram mais uniformes, isso pode representar que eles tiveram um maior consenso nas respostas que provavelmente foi um reflexo das ações tomadas pelo colegiado, como por exemplo, a ação de preparar aulas específicas sobre determinadas competências diagnosticadas como ruins, a partir da aplicação dos simulados anteriores.

A Tabela 1 também apresenta a porcentagem média de acertos das duas aplicações. A Turma 01 teve um prejuízo de $-9.91 \%$ no rendimento da segunda aplicação. O maior ganho foi de $23.01 \%$ na segunda aplicação em relação a primeira, 
pelos alunos da Turma 04. Esse alto ganho é reflexo das ações específicas que foram tomadas pelo colegiado do curso, pelo fato desses alunos serem propensos a representarem o curso de BSI no Enade 2020. A Turma 02 teve um ganho de $4.04 \%$ e a Turma 03 de $1.91 \%$. São exemplos das ações específicas executadas: apresentação dos resultados para as turmas; execução de aulas direcionadas para a resolução das questões e execução de aulas direcionadas para conteúdos específicos do curso para melhorar competências que haviam tido um baixo rendimento.

Tabela 1. Porcentagem média de acertos e Coeficiente alfa de Cronbach

\begin{tabular}{|c|c|c|c|c|}
\hline Turma & Média $1^{\circ}$ Apl & Cronbach $1^{\circ}$ Ap & Média $2^{\circ}$ Apl & Cronbach $2^{\circ}$ Ap \\
\hline Turma 01 & $51.87 \%$ & 0.202 & $41.96 \%$ & 0.556 \\
\hline Turma 02 & $36.36 \%$ & -0.978 & $40.74 \%$ & 0.709 \\
\hline Turma 03 & $42.85 \%$ & -0.633 & $44.76 \%$ & -0.570 \\
\hline Turma 04 & $39.21 \%$ & 0.512 & $62.22 \%$ & 0.748 \\
\hline
\end{tabular}

Analisando o desempenho de cada estudante, na Turma 01, foi possível perceber uma diminuição da porcentagem de acertos na segunda aplicação, percebeu-se que apenas quatro alunos aumentaram o seu rendimento na segunda aplicação. Na Turma 02, ocorreu a maior quantidade de ganho no rendimento dos alunos, cinco alunos tiveram ganho e quatro alunos tiveram uma diminuição. Na Turma 03, três alunos tiveram ganho e quatro alunos tiveram um menor rendimento. Na Turma 04, que representa a turma com o maior rendimento na segunda aplicação, teve ganho de rendimento em sete alunos e outros dois tiveram uma perda no percentual de acerto.

A maior diminuição no rendimento na segunda aplicação, foi do aluno St16 da Turma 01 . O aluno St16 acertou $36.97 \%$ a menos na segunda aplicação. O aluno St16 apresenta no semestre 2020.1, a nota 8.53 como Coeficiente de Rendimento Acadêmico (CRA). Isso pode representar que pode ter existido outros fatores que interferiram no rendimento desse e de outros alunos durante a segunda aplicação. Um grande fator que pode ser exposto durante a segunda aplicação é que a prova foi realizada totalmente a distância por causa do período de pandemia da COVID-19 que o mundo estava vivenciando. Os alunos St4, St5, St6, St15, St19, St24, St26 e o St27, também tiveram uma diminuição do rendimento, que representa mais que $20 \%$ a menos na segunda aplicação. Esses alunos possuem CRA, respectivamente de 5.57, 6.04, 8.02, 8.33, 8.78, $8.42,7,4$ e 8.11 .

$\mathrm{O}$ aluno St36 teve um ganho de mais de $60 \%$, o que representa o maior ganho. Esse aluno possui CRA 5.42. De acordo com o histórico desses alunos no curso, o colegiado suspeita que ele tenha realizado consulta no momento da resolução das questões, sendo que todos os estudantes foram orientados a não realizarem nenhum tipo de consulta. Para isso, foi fornecida uma pontuação de participação, e não uma pontuação pelo rendimento, como foi feito na primeira aplicação. Os alunos St3, St18, St22, St23, St31, St35, St37, St39, St40, St41 e St42, também tiveram um aumento no 
rendimento, que representa mais que $20 \%$ na segunda aplicação. Esses alunos possuem CRA, respectivamente de 6.9, 8.37, 8.08, 7.93, 8.47, 7.35, 7.95, 8.02, 7.02 e 7.88.

A Figura 4 apresenta dois gráficos correspondentes a média de acertos das competência IV e VII durante a primeira e a segunda aplicação. Essas duas competências foram escolhidas para serem representadas graficamente pelo fato de elas terem sido representadas por questões nas duas aplicações de todas as turmas. Nos gráficos, T1 1 representa a primeira aplicação da Turma 01, T1 2 representa a segunda aplicação da Turma 01, e assim sucessivamente. Os gráficos também apresentam o intervalo de confiança calculado utilizando a função t.test() do software RStudio ${ }^{3}$, levando em consideração 95\% de confiabilidade. Os gráficos da Figura 4 demonstram que a Turma 01 possui o menor intervalo de confiança (IC) na primeira e segunda aplicação da competência IV, como também na segunda aplicação da competência VII. Os dados das respostas da Turma 02 e Turma 03 possuem um alto intervalo de confiança nas duas aplicações de todas as competências. A Turma 04 possui o menor intervalo na segunda aplicação da competência VII, mas nas demais os intervalos acabaram sendo altos.

De acordo com o cálculo do IC, as respostas dos estudantes da Turma 01 na T1 1, T1 2 da competência IV (Figura 5.a) e T1 2 da competência VII (Figura 5.b), como também da Turma 04 na T4 2 da competência VII (Figura 5.b) são mais confiáveis por possuírem um intervalo de confiança menor. Como sabe-se que, neste caso, no intervalo de confiança, existe $95 \%$ de chance de conter a média dos alunos de determinada aplicação em uma turma específica, então quanto maior a média e menor o intervalo de confiança, melhor o resultado da turma.

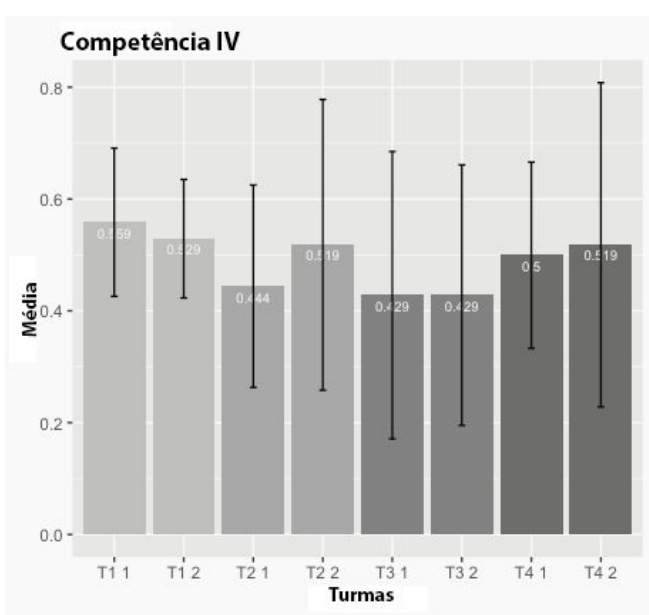

(a)

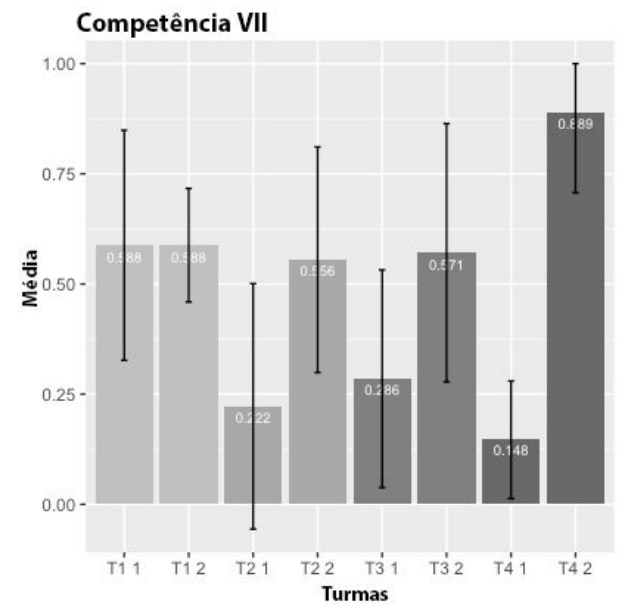

(b)

Figura 4. Resultado das competências IV e VII

\section{Feedback dos professores}

O feedback dos professores foi importante para entender as percepções dos sujeitos que compuseram todo o processo. Para isso, foi desenvolvido um questionário com cinco afirmações que os professores poderiam Concordar Totalmente, Concordar parcialmente, ficar Neutro, Discordar Parcialmente ou Discordar Totalmente. As

\footnotetext{
${ }^{3}$ https://rstudio.com
} 
afirmações foram colocadas em um formulário online, o qual também possuía uma questão aberta onde era possível deixar algum comentário sobre todo o processo.

O total de oito professores, responderam ao formulário. A primeira afirmação que dizia "Q1 - O processo utilizado no curso de Bacharelado em Sistemas de Informação para diagnosticar competências utilizando o sistema Questione foi satisfatório", $62.5 \%$ (5) dos professores concordaram totalmente e $37.5 \%$ (3) concordaram parcialmente. A segunda questão afirmou "Q2 - Por meio do sistema Questione, foi possível identificar quais competências os estudantes do curso de Bacharelado em Sistemas de Informação precisavam de reforço", nessa, 87.5\% (7) dos professores concordaram totalmente e $12.5 \%$ (1) concordaram parcialmente. A terceira questão afirmou "Q3- Por meio do sistema Questione foi possível diagnosticar estudantes específicos em relação à turma a qual pertenciam", sendo que $100 \%$ (8) dos professores concordaram totalmente com a afirmação. A quarta questão afirmou "Q4 A aplicação dos dois simulados foi o suficiente para diagnosticar os estudantes e pensar em estratégias mais específicas para serem trabalhadas no curso", nessa, 25\% (2) dos professores concordaram totalmente e $75 \%$ (6) dos professores concordaram parcialmente. Na última foi afirmado que "Q5 - O uso do sistema Questione foi necessário para facilitar a catalogação das questões por competência, aplicação das avaliações e análise das respostas", nessa 87.5\% (7) dos professores concordaram totalmente e $12.5 \%$ (1) ficaram neutros.

Por meio da questão aberta, os professores deixaram elogios ao processo utilizado, o que pode-se perceber também pelas respostas nas afirmativas. Os professores escreveram que aplicações mais frequentes podem trazer resultados mais precisos. Expressaram também que o sistema serviu como um instrumento que foi embasado científico-técnico e pedagógico para diagnóstico e identificação do perfil do aluno do curso de BSI, e também serviu como um atuante na evolução dos estudantes no que tange as competências necessárias no ENADE.

Dois professores relataram que utilizaram o sistema em suas disciplinas, e isso é interessante pelo fato de que esses professores sentiram a necessidade de diagnosticar os estudantes em relação às competências que estão relacionadas às suas disciplinas. Um dos professores relatou que ao utilizá-lo na sua disciplina, ele pôde traçar de forma mais precisa o perfil das habilidades e competências dos estudantes, bem como organizar avaliações mais direcionadas as deficiências de cada estudante individualmente.

Uma outra observação dada no feedback dos professores, foi que os alunos deveriam passar por um treinamento para que se adequem a estrutura e tipo das questões que foram utilizadas nos simulados, uma vez que esse tipo de questão, geralmente não é adotada pelos professores na construção de suas avaliações das disciplinas. A estrutura das questões utilizadas nos dois simulados é a mesma estrutura utilizada nas questões do Enade. Essa estrutura é formada por: texto base, enunciado, gabarito e distratores. Em relação ao tipo, foram utilizadas questões do tipo: item de resposta múltipla, item de resposta única e asserção-razão.

\section{Considerações finais}

Este trabalho apresentou um estudo de caso realizado em um curso de BSI utilizando o sistema Questione que foi desenvolvido para armazenar um banco de questões catalogado por competências, objetos de conhecimento e curso. Para a realização do estudo de caso, foram realizados dois simulados com 42 alunos de quatro 
turmas distintas. Ao analisar todos os elementos desta pesquisa, pode-se concluir que o sistema foi fundamental para sistematizar o processo de avaliação diagnóstica, permitindo que a catalogação das questões e aplicação dos simulados se tornasse uma tarefa simples.

Por meio da inserção do sistema dentro do processo, pôde-se também conseguir identificar estudantes com dificuldade de forma específica, como também foi possível identificar competências que precisam ser melhor desenvolvidas em cada turma, e também no âmbito do curso. Dessa forma, conhecendo melhor quais as competências precisam ser melhor desenvolvidas, o colegiado do curso pode planejar estratégias específicas na tentativa de melhorar o desempenho dos estudantes e isso pode impactar consideravelmente na vida acadêmica e profissional do sujeito.

Este trabalho foi desenvolvido na perspectiva de um estudo de caso para um curso de BSI e os resultados se limitam a esse curso, seu colegiado e seus estudantes especificamente. Espera-se que essa pesquisa possa ter continuidade, podendo ser comparados alunos de cursos de Instituições distintas, como também analisar mais aplicações de provas e novas estratégias, pois esta pesquisa se limitou a apenas duas aplicações.

\section{Referências}

BRASIL. Sistema nacional de avaliação da educação superior - sinaes. 2004. Disponível em: http://www.planalto.gov.br/ccivil 03/ ato2004-2006/2004/lei/110.861.htm.

BRASIL. Portaria Inep $\mathrm{n}^{\mathrm{o}} 513$ de 6 de junho de 2017. 2017. Disponível em: http://download.inep.gov.br/educacao_superior/enade/legislacao/2017/sistemas de i nformacao - portaria n 513 de 6 de junho de 2017.pdf.

BRASIL. Resolução $\mathrm{n}^{\mathrm{o}}$ 5, de 16 de novembro de 2016. 2016. Disponível em: http://portal.mec.gov.br/index.php?option $=$ com docman \&view $=$ download\&alias $=52$ 101-rces005-16-pdf\&category_slug=novembro-2016-pdf\&Itemid=30192.

Hinojo-Lucena, F.-J.; Aznar-Díaz, I.; Cáceres-Reche, M.-P.; Trujillo-Torres, J.-M.; Romero-Rodríguez, J.-M. Sharenting: Internet addiction, self-control and online photos of underage children. Comunicar Rev. Cient. Comunicación Educ. 2020, 28.

Hora, H. R. M.; Monteiro, G. T. R; Arica, J. Confiabilidade em Questionários para Qualidade: Um estudo com o coeficiente Alfa de Cronbach. Produto \& Produção, vol. 11, n. 2, p. 85-103, jun. 2010. Disponível em: https://www.seer.ufrgs.br/ProdutoProducao/article/viewFile/9321/8252. Acesso em: 24 de Junho de 2020.

Larman, C. Utilizando UML e padrões [recurso eletrônico]: uma introdução à análise e ao projeto orientados a objetos e ao desenvolvimento iterativo. 3 ed. Porto Alegre: Bookman, 2007.

Lima, P. S. N.; Ambrósio, A. P. L.; Félix I. M.; Brancher, J. D.; Ferreira, D. J. Content Analysis of Student Assessment Exams. IEEE. 2018. Disponível em: https://ieeexplore.ieee.org/document/8659169. Acesso em: 02 de Julho de 2020.

Questione. Sistema Questione. Disponível em: https://questione.ifce.edu.br/. Acesso em: 01 de Setembro de 2020. 